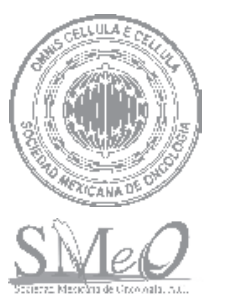

SOCIEDAD MEXICANA DE ONCOLOGÍA, A.C

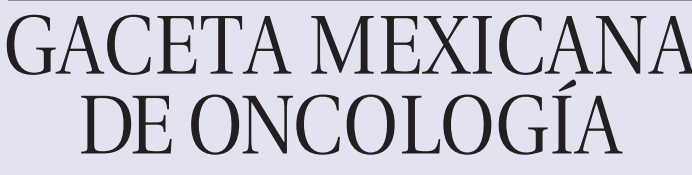

www.gamo-smeo.com

\title{
EDITORIAL
}

\section{La genética como herramienta en la práctica diaria oncológica}

\author{
Herbert García-Castillo ${ }^{1, *}$ y Francisco Javier Ochoa-Carrillo²
}

\begin{abstract}
${ }^{1}$ Dirección General, Fundación Vida en Genoma A.C., ²Departamento de Cirugía Oncológica, Instituto Nacional de Cancerología, Hospital Ángeles del Pedregal, Ciudad de México, México
\end{abstract}

Recibido el 11 de diciembre de 2016; aceptado el 25 de febrero de 2017

Disponible en Internet el 14 de julio de 2017

La consulta de oncología se enriquece con la genética, una nueva ciencia que está revolucionando la práctica clínica oncológica, contribuye con elementos para entender la fisiopatología del cáncer y permite un manejo, diagnóstico y tratamiento integral del paciente, desde el conocimiento de nuevos blancos terapéuticos, pasando por la integración de nuevos diagnósticos clínicos de cáncer hereditario, hasta el pronóstico y tratamiento de cánceres esporádicos.

Actualmente hay una gran cantidad de estudios y herramientas genéticas disponibles: test para cáncer hereditario, estudios de expresión para la predicción de metástasis, farmacogenética, microarreglos, hibridación genómica comparativa, etc., pero ¿en qué consisten estos estudios?, ¿en qué caso hay que pedirlos?, ¿cuáles son los pacientes candidatos?, ¿es mejor pedir estudios individuales o paneles de genes?, ¿qué requerimientos deben tener los laboratorios que hagan estas pruebas?, ¿en qué casos se debe pedir una interconsulta con genética? Éstas y otras preguntas son las que se hace el oncólogo en el momento de enfrentarse a la decisión de prescribir un estudio genético.

Estos cuestionamientos no son fáciles de responder, y muchos de ellos requieren un conocimiento de las bases de la genética clínica y de los temas específicos en los que se aplica ese conocimiento. A partir de esta edición comenzamos una serie de artículos, con el fin de actualizar a los oncólogos en la aplicación de la genética a la consulta oncológica. Empezamos con el artículo de la revista de esta edición llamado «Conceptos básicos de genética clínica para la práctica oncológica». Al igual que cualquier otra especialidad, la genética clínica maneja su propia terminología, que en algunos casos puede ser lejana para el oncólogo. Este artículo introduce este mundo con un lenguaje sencillo y ejemplos didácticos para su comprensión.

Trataremos con más profundidad en siguientes números temas de asesoramiento genético, alteraciones genéticas en el cáncer, biomarcadores en oncología, recomendaciones in ternacionales para la utilización de pruebas genéticas en la práctica oncológica, síndromes de cáncer hereditario, genes versus paneles, farmacogenética, pruebas de expresión genética, valoración y manejo del riesgo en el cáncer de mama y colon hereditario, cirugía profiláctica y abordajes quirúrgicos con base en estudios moleculares, costo-efectividad en el manejo del cáncer hereditario, visión del paciente y abor daje de equipos interdisciplinarios en el manejo del cáncer hereditario.

Hay varios ejemplos de la utilidad de la genética en la práctica oncológica. En los últimos años han cambiado los medicamentos que se usan en oncología con base en el conocimiento de las vías moleculares y biomarcadores (molé culas específicas que se sobreexpresan en el cáncer)', los cuales tienen un gran valor en la predicción de la respuesta a la terapia y han cobrado relevancia en la práctica oncoló= gica diaria, como el uso de HER2 o EGFR, beneficiando a un gran subgrupo de pacientes en los últimos años (Tabla 1).

Actualmente en oncología hay más de 50 fármacos con biomarcadores genéticos que están incorporados en las descripciones e insertos de fármacos aprobados por la Food and Drug Administration (FDA). Dentro de esta lista hay algunos fármacos que se prescriben especialmente cuando se encuentra una alteración genética; es el caso del tratamiento

*E-mail para correspondencia: herbertgarcia@vidaengenoma.org (H. García-Castillo) 
Tabla 1. Biomarcadores de uso frecuente en oncología

\begin{tabular}{|c|c|c|c|c|}
\hline Aprobación FDA & Cáncer & Pacientes beneficiados & Fármaco & Biomarcador \\
\hline Noviembre de 2004 & CA pulmón & $15 \%$ & Erlotinib & EGFR \\
\hline Abril de 2003 & $\begin{array}{l}\text { Leucemia mieloide } \\
\text { crónica }\end{array}$ & $95 \%$ & Imatinib & BCR-ABL \\
\hline Septiembre de 1998 & CA mama & $15-20 \%$ & Trastuzumab & HER2 \\
\hline
\end{tabular}

Tabla 2. Indicación o contraindicación en fármacos aprobados por la FDA de acuerdo a la presencia de mutaciones

\begin{tabular}{|c|c|c|c|c|}
\hline Fármaco & Tipo de cáncer & Gen & Mutación & Implicación \\
\hline $\begin{array}{l}\text { Afatinib } \\
\text { Erlotinib } \\
\text { Gefitinib } \\
\text { Osimertinib }\end{array}$ & $\begin{array}{l}\text { Cáncer pulmonar de } \\
\text { células no pequeñas } \\
\text { metastásico }\end{array}$ & EGFR & $\begin{array}{l}\text { Deleción de } \\
\text { exones 19-21 } \\
\text { L858R } \\
\text { T790M }\end{array}$ & Indicación \\
\hline $\begin{array}{l}\text { Cobimetinib } \\
\text { Dabrafenib } \\
\text { Pembrolizumab } \\
\text { Trametinib } \\
\text { Vemurafenib }\end{array}$ & Melanoma metastásico & $B R A F$ & $\mathrm{~V} 600 \mathrm{E} / \mathrm{K}$ & Indicación \\
\hline Olaparib & $\begin{array}{c}\text { Cáncer de ovario } \\
\text { avanzado }\end{array}$ & $B R C A 1 / 2$ & $\begin{array}{l}\text { Mutaciones de línea } \\
\text { germinal (heredadas) }\end{array}$ & Indicación \\
\hline $\begin{array}{l}\text { Cetuximab } \\
\text { Panitumumab }\end{array}$ & $\begin{array}{l}\text { Cáncer colorrectal } \\
\text { metastásico }\end{array}$ & KRAS & $\begin{array}{l}\text { Deleción de exones } 2 \text {, } \\
3 \text { y } 4 \text { (codones } 12 \text {, } \\
13,59,61,117 \text { y } 147 \text { ) }\end{array}$ & Contraindicación \\
\hline
\end{tabular}

del cáncer pulmonar de células no pequeñas con afatinib, erlotinib, gefitinib y osimertinib; de la quimioterapia en el melanoma metastásico con cobimetinib, dabrafenib, pembrolizumab, trametinib y vemurafenib, y del tratamiento del cáncer de ovario avanzado con olaparib, estos fármacos tiene tasas de respuesta del 30 al 70\%. Por el contrario, algunas mutaciones son una contraindicación para la prescripción de ciertos medicamentos, como cetuximab o panitumumab² (Tabla 2).

Cada vez es más frecuente el uso de paneles de expresión génica como MammaPrint ${ }^{\circledR}$ y OncotypeDx ${ }^{\circledR}$ en pacientes con cáncer de mama en estadios tempranos con el fin de asignarlos a un grupo de riesgo y discernir qué pacientes se pueden beneficiar de quimioterapia adyuvante y qué pacientes no la requieren.

MammaPrint ${ }^{\circledR}$ es un estudio de expresión de 70 genes que utiliza tecnología de microarreglos, requiere tejido congelado y se utiliza en pacientes con cáncer de mama en estadios I y II con ganglios negativos o con ganglios positivos de 1-3, para identificar a las pacientes que se pueden beneficiar de la quimioterapia adyuvante con base en el riesgo genómico (alto o bajo) de recurrencia del cáncer a distancia a 5 y 10 años. El estudio prospectivo MINDACT, que sigue a una cohorte de más de 6,000 pacientes, ha encontrado que las pacientes de alto riesgo clínico y bajo riesgo genómico poscirugía y sin quimioterapia tienen una sobrevida a cinco años sin metástasis a distancia del $94.7 \%$ (intervalo de confianza [IC] 95\%: 92.5-96.2 $)^{3}$.

OncotypeDx ${ }^{\circledR}$ es un estudio de expresión de 21 genes que incluye ER, PR, HER2 y Ki67 en cáncer de mama para mujeres positivas a ER, negativas a HER2 y negativas a metástasis de ganglios linfáticos. La tecnología empleada es una reacción en cadena de la polimerasa con transcriptasa inver sa (RT-PCR) que requiere tejido embebido en parafina. Las pacientes se clasifican de acuerdo a un score de recurrencia para identificar a las que se benefician de una quimioterapia adyuvante: las pacientes con score de $0-10$ son asignadas a recibir terapia endocrina, a las que tienen un valor mayor a 26 se les da quimioterapia y terapia endocrina, y las pacientes con un score de entre 11 y 25 quedan en un grupo indefinido, debido a que no se ha definido el beneficio de la quimioterapia en su caso. Este perfil de expresión se considera un predictor de la eficacia del tamoxifeno y de la quimioterapia adyuvante. El estudio prospectivo TAILORx, realizado en más de 10,000 pacientes, mostró que el $15.9 \%$ de las pacientes pertenecían al grupo de 0-10 de riesgo de recurrencia, recibieron únicamente terapia endocrina y tuvieron una tasa de sobrevida libre de enfermedad invasiva a cinco años del 93.8\% (IC 95\%: 92.4-94.9) ${ }^{4}$.

Además de la aplicación de los estudios genéticos en la prescripción de quimioterapia, un campo muy interesante son los estudios genéticos en pacientes con cáncer hereditario. Se estima que el $5-10 \%$ de los cánceres son hereditarios, y su manejo clínico es diferente al de un cáncer esporádico.

Por ejemplo, en el síndrome de cáncer de mama y ovario hereditario positivo para la mutación en $B R C A$ el riesgo de presentar cáncer de mama y/o cáncer de ovario ocurre hasta en el 41-90\% de los casos, y también se presenta un aumento de la recurrencia en el cáncer de mama contralateral hasta del $32 \%$ a los 10 años y del $44 \%$ a los 70 , por lo que se recomienda la mastectomía bilateral en pacientes de reciente diagnóstico $\mathrm{y}$, debido al riesgo de cáncer de ovario de hasta el $44 \%$ a los 70 años, se recomienda la salpingooforectomía reductora del riesgo después de los 35 
años con paridad satisfecha. Estos procedimientos ayudan a reducir el riesgo de cáncer de mama y ovario un 95 y un $90 \%$, respectivamente ${ }^{5}$. Cabe señalar que algunas pacientes asintomáticas no prefieren la opción de las cirugías reductoras de riesgo, por lo que la vigilancia estricta con estudios de imagen y marcadores séricos semestralmente es la opción. En la actualidad está disponible el fármaco olaparib para pacientes con cáncer de ovario avanzado positivo a mutación heredada en los genes BRCA y se encuentran en estudio en fase III fármacos inhibidores de la poli-ADP-ribosa polimerasa para el cáncer de mama positivo a BRCA.

Los criterios clínicos en el cáncer hereditario cada vez son menos rigurosos como método de tamizaje primario para incluir el mayor número de pacientes candidatos a estudios genéticos. Los criterios del National Comprehensive Cancer Network (NCCN) para test genético en el síndrome de cáncer de mama y ovario hereditario, incluyen, entre otros, pacientes con alguno de los siguientes criterios: pacientes con cáncer de mama antes de los 45 años, cáncer de ovario a cualquier edad, cáncer de mama triple negativo antes de los 60 años, dos cánceres en la familia del espectro (mama, ovario, tubárico, próstata, páncreas y peritoneo $)^{5}$. Se estima que en México 1 de cada 5 pacientes con cáncer de mama cumplen estos criterios.

Hay disponibles estudios en genes de alta penetrancia como $B R C A$, pero también hay paneles de varios genes, de hasta 30 o más genes relacionados con cáncer hereditario. El clínico debe conocer el grado de penetrancia de los diversos genes en cáncer hereditario y los diagnósticos diferenciales para saber si es conveniente prescribir un panel genético; no todos los resultados son clínicamente accionables.

La genética es una ciencia fascinante y muy prometedora para la oncología. Ilustramos algunas de las aplicaciones relevantes de la genética en la práctica oncológica diaria, y en números posteriores se complementará la información proporcionada. Empezamos en esta edición con las bases de la genética clínica en el artículo titulado «Conceptos básicos de genética clínica para la práctica oncológica»; esperamos que sea de su interés y contribuya a actualizar la práctica clínica actual.

\section{BIBLIOGRAFÍA}

1. Ferté C, André F, Soria JC. Molecular circuits of solid tumors: prognostic and predictive tools for bedside use. Nat Rev Clin Oncol. 2010;7(7):367-80.

2. US Food and Drug Administration. Table of Pharmacogenomic Biomarkers in Drug Labels. [Internet] Consultado el 15 de enero de 2017. Disponible en: http: //www.fda.gov/Drugs/ScienceResearch/ResearchAreas/ Pharmacogenetics/ucm083378.htm.

3. Cardoso F, van't Veer LJ, Bogaerts J, et al. 70-Gene Signature as an Aid to Treatment Decisions in Early-Stage Breast Cancer. N Engl J Med. 2016;375(8):717-29.

4. Sparano JA, Gray RJ, Makower DF, et al. Prospective Validation of a 21-Gene Expression Assay in Breast Cancer. $N$ Engl J Med. 2015;373(21):2005-14.

5. National Comprehensive Cancer Network. NCCN Clinical Practice Guidelines in Oncology: Genetic/Familial High-Risk Assessment: Breast and Ovarian, 2017. [Internet] Consultado el 15 de enero de 2017. Disponible en: https: //www.nccn.org/professionals/physician_gls/f_guidelines.asp. 